Research Article

\title{
Design Optimization of Catalytic Converter to reduce Particulate Matter and Achieve Limited Back Pressure in Diesel Engine by CFD
}

\author{
B.Balakrishna $\dot{A}^{*}$ and Srinivasarao Mamidala $\dot{A}$

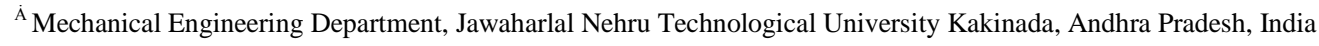 \\ Accepted 10 January 2014, Available online 01 February 2014, Special Issue-2, (February 2014)
}

\begin{abstract}
Now a days the global warming and air pollution are big issue in the world. The 70\% of air pollution is due to emissions from an internal combustion engine. The harmful gases like, $N O_{X} \mathrm{CO}$, unburned $\mathrm{HC}$ and particulate matter increases the global warming, so catalytic converter plays an vital role in reducing harmful gases, but the presence of catalytic converter increases the exhaust back pressure due to this the volumetric efficiency will decrease and fuel consumption is higher. So analysis of catalytic converter is very important. The rare earth metals now used as catalyst to reduce $\mathrm{NO}_{X}$ are costly and rarely available. The scarcity and high demand of present catalyst materials necessitate the need for finding out the alternatives. Among all other particulate filter materials, knitted steel wire mesh material is selected as filter materials in this paper. Through Computational Fluid Dynamics (CFD) analysis, various models with different wire mesh grid size combinations were simulated using the appropriate boundary conditions. The comparison of back pressure of different catalytic converter models is made in this paper.
\end{abstract}

Keywords: Through Computational Fluid Dynamics (CFD), Catalytic bead, Particulate Matter (PM).

\section{Introduction}

Internal Combustion engines generate undesirable emissions during the combustion process, which include, $\mathrm{NO}_{\mathrm{X}} \mathrm{CO}$, unburned $\mathrm{HC}$, smoke etc. Apart from these unwanted gases, it produces Particulate Matter (PM) such as lead, soot. All these pollutants are harmful to environment and human health. They are the main causes for greenhouse effect, acid rain, global warming etc. The simplest and the most effective way to reduce $\mathrm{NO}_{\mathrm{X}}$ and PM, is to go for the after treatment of exhaust. Devices developed for after treatment of exhaust emissions includes thermal converters or reactors, traps or filters for particulate matters and catalytic converters. The most effective after treatment for reducing engine emission is the catalytic converter found on most automobiles and other modern engines of medium or large size.

The catalyst and filter materials placed inside the catalytic converter increase back pressure. This increase in back pressure causes more fuel consumption, and in most cases, engine stalling might happen. The filtration efficiency and back pressure are interrelated. If maximum filtration efficiency using very fine grid size wire meshes, is achieved, the back pressure will also be increased, which causes more fuel consumption. On the other hand, if larger grid size wire meshes are used, back pressure will be less, but the filtration efficiency will also be reduced, which does not help in meeting the present emission norms. With the help of CFD analysis, it is attempted to

*Corresponding author: B.Balakrishna

DOI: http://dx.doi.org/10.14741/ijcet/spl.2.2014.124 find out the optimum solution to get maximum filtration efficiency with limited back pressure developed inside the catalytic converter.

It has been observed by (Andreassi, et al, 2004) and investigated that the role of channel cross-section shape on mass and heat transfer processes. The development of catalytic converter systems for automotive applications is, to a great extent, related to monolith catalyst support materials and design. In this paper improvements of converter channels fluid-dynamics aiming to enhance pollutant conversion in all the engine operating conditions are studied and (Rajadurai, et al, 2006) investigated the effect of Knitted wire mesh substrates with different geometry and channels on the back pressure of catalytic converter. The primary requirements of exhaust after treatment systems are low back pressure, low system weight, better emission performance and lower cost. Combinations of these properties provide better engine performance and higher system value. Combinations of these properties provide better engine performance and higher system value (Ekstrom and Andersson, et al, 2002) Investigated the pressure drop behavior of catalytic converter for a number of different substrates, suitable for high performance IC-engines, regarding cell density, wall thickness and coating. The measurements have been performed on an experimental rig with room-air flow and hot-air flow. The data has been used to develop an empirical model for pressure drop in catalytic converters. (Narasimha Kumar, et al, 2011) Investigations have been carried out for reducing pollutants from a variable 
compression ratio, copper-coated spark ignition engine fitted with catalytic converter containing sponge iron catalyst run with gasohol (blend of $20 \%$ ethanol and $80 \%$ gasoline by volume).The major pollutants emitted from spark ignition engine are carbon monoxide (CO) and unburnt hydrocarbons (UHC). (Mohiuddin and Nurhafez, et al, 2007) conducted an experiment to study the performance and conversion efficiencies of ceramic monolith three-way catalytic converters (TWCC) employed in automotive exhaust lines for the reduction of gasoline emissions. Two ceramic converters of different cell density, substrate length, and hydraulic channel diameter and wall thickness were studied to investigate the effect of varying key parameters on conversion efficiencies and pressure drop.

(Muthaiah, et al, 2010) conducted an experimental test on a $10 \mathrm{hp}$, twin-cylinder, and four-stroke, direct-injection, vertical diesel engine. At present, the wall flow ceramic substrate is used as filters which are expensive and also offer more back pressure resulting in more fuel consumption. In the present study, catalytic-coated steel wire mesh materials with coarse, fine, and very fine grid sizes are used for PM filtration. The soluble organic fractions of diesel PM is oxidized by DOC system. So this provides strong motivation for development of improved catalytic converter.

\section{Selection of filter material}

There are many types of filter materials are used in internal combustion engine. They are Ceramic monolith, ceramic foam, steel wire meshes, ceramic silicon fiber, porous ceramic honey comb are the few types of filter materials. Out of these filter materials, steel wire mesh is selected as filter material because knitted steel wire mesh material is ranked first for its collection efficiency of particulate matter.

The other reasons for its selection are,

- Thermal stability during regeneration.

- Good mechanical properties.

- Long durability.

- $\quad$ Easy availability and less cost

\section{Construction}

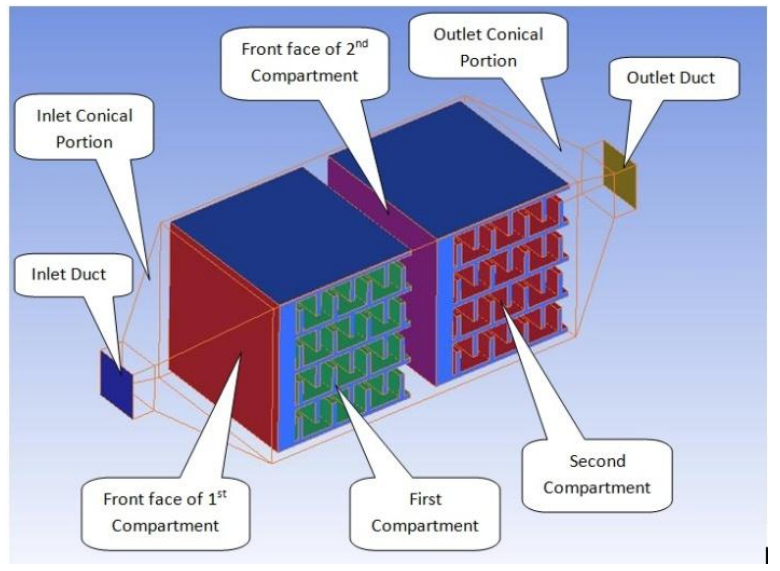

Fig.1 3D view of Catalytic convertor
The catalytic converter consist of

- Inlet duct

- Inlet conical potion

- First compartment

- Second compartment

- Outlet conical portion

- Outlet duct

All these parts have been shown in the figure 1. The front of $1^{\text {st }}$ compartment and $2^{\text {nd }}$ compartment are monitored for $\mathrm{CO}$ mass fraction and pressure distribution using CFD analysis.

\section{Wire mesh specifications}

Two wire mesh models have been studied MC-1 and MC2 respectively as shown in the figure.

Void space in $\mathrm{MC}-1$ is $64 \%$ for each compartment, while in MC-2 it is about $0.68 \%$.

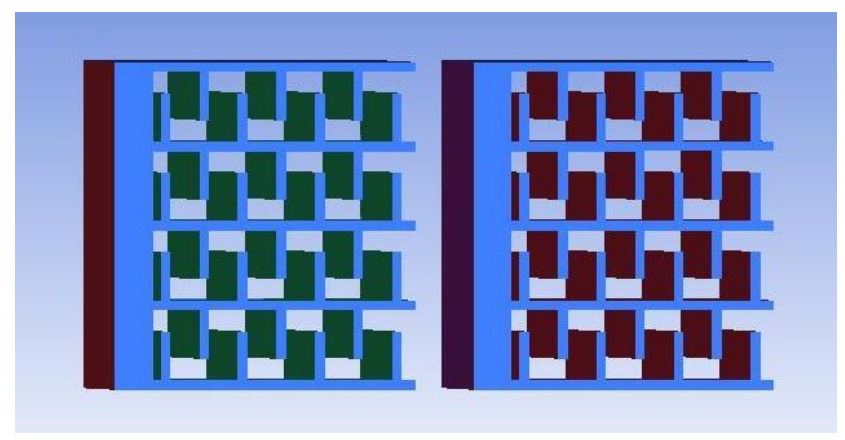

Fig.2 3D view of Catalyst bed for MC-1

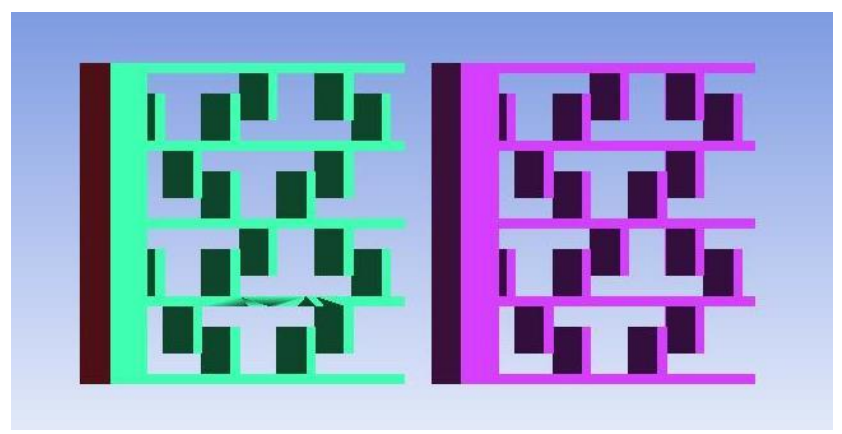

Fig.3 3D view of Catalyst bed for MC-2

\section{Working principle}

In the first compartment the exhaust gas passes through catalytic beads and steel wire mesh material which are coated with metal catalyst. As the hot gases contact the catalyst and the coated wire mesh, most of the exhaust pollutants such as $\mathrm{CO}$, gaseous hydrocarbons, and unburned fuel and lube oil, toxic aldehydes etc. are oxidized to $\mathrm{CO}_{2}$ and water, thus reducing harmful emissions. In the second compartment ammonia plus exhaust gas is passed through catalytic beads and steel wire mesh material which are coated with metal catalyst. Ammonia derived from urea is used to reduce $\mathrm{NO}_{\mathrm{X}}$ from diesel engines. Ammonia is produced on-board by rapid hydrolysis of nonhazardous form of urea solution. In 
second compartment the $\mathrm{NO}_{\mathrm{X}}$ are converted into nitrogen and oxygen.

In both compartments a part of the exhaust gas passes through the wire mesh layers which trap a portion of the soot. The remaining exhaust gas flows out to the neighboring bead placed in the same line - similar to a flow-through substrate. The soot trapped in the wire mesh material is combusted by the $\mathrm{NO}_{2}$ that is generated by the upstream catalyst and thus the filter is regenerated continuously. If a situation occurs where filter regeneration is stopped and a saturation point occurred with the collected soot, the wire meshes placed over the catalytic beads will not plug as happened in wall flow filter. As the path of the gas is not totally blocked, the back pressure developed inside the catalytic converter is very much limited and no further increase in back pressure can happen beyond certain limit, irrespective of the soot loading over a period of time. A compressed air cleaning process is suggested to clean the PM deposition on steel wire meshes and catalytic beads. In this process, two numbers of compressed air inlet points are placed in between two compartments at diametrically in opposite position.

\section{Modeling and meshing}

The geometry of catalytic converter is modeled and meshed in ICEM CFD. And the flow equations solved in ANSYS FLUENT.

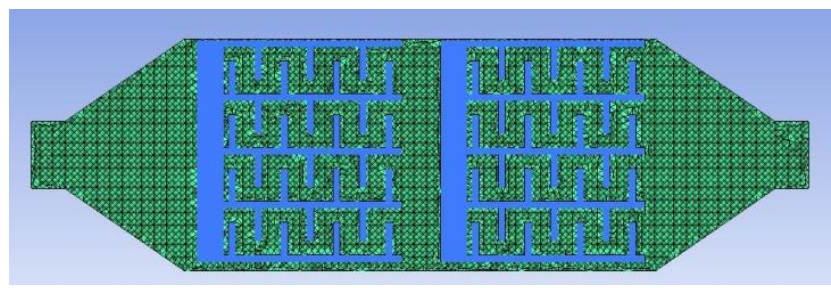

Fig.4 The meshed catalytic convertor

\subsection{Domain conditions}

The continuity and 3-dimensional momentum equations will be solved for the isothermal flow modeling. Turbulence will be modeled by k- $\varepsilon$ RNG turbulence model appropriate to account for high velocities and strong streamline curvature in the flow domain. The reference pressure will be set at 1.33 atm and all pressure inputs and outputs will be obtained as gauge values with respect to this. Air will be the working fluid considered to be operating at $350 \mathrm{C}$ and 1.35 bar.

Table 1 The material properties under these conditions are:

\begin{tabular}{|l|l|}
\hline Property & Air \\
\hline Density (kg/m3) & 0.7534 \\
\hline Viscosity (Pa.s) & $3.0927 \times 10-5$ \\
\hline Specific heat (J/kgK) (not used) & 1056.6434 \\
\hline $\begin{array}{l}\text { Thermal conductivity (W/mK) } \\
\text { (not used) }\end{array}$ & 0.0242 \\
\hline
\end{tabular}

\section{Boundary condition}

The engine selected for this study is a four stroke twin cylinder ( $80 \mathrm{~mm}$ bore and $110 \mathrm{~mm}$ stroke length) water cooled diesel engine. The engine displacement is calculated as $603 \mathrm{~cm}^{3} / \mathrm{s}$ for the assumed vehicle speed of $60 \mathrm{~m} / \mathrm{s}$. This gives the necessary inlet speed to the catalytic converter with inlet cross section of $50 \mathrm{~mm} \times 50 \mathrm{~mm}$ as approximately $25.05 \mathrm{~cm} / \mathrm{s}$.

Therefore, inlet velocity will be maintained at a slightly higher value of $0.3 \mathrm{~m} / \mathrm{s}$ and the operating pressure will be maintained at 1.33 atm. The outlet will be considered as a pressure outlet at zero gauge pressure. A high turbulence intensity of $10 \%$ will be flow will be assumed for the inlet while the hydraulic diameter at the inlet will be considered to close the turbulence model equations.

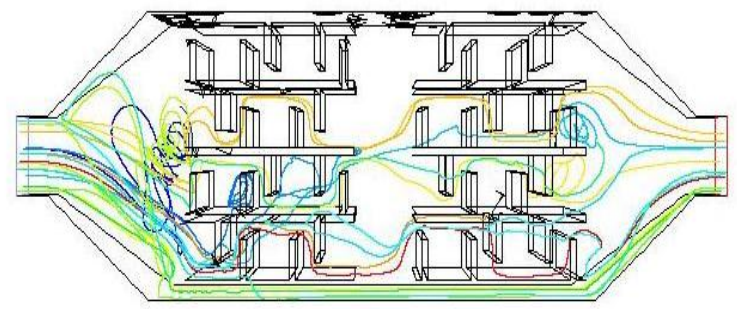

Fig.5 Pathlines of CO inside catalytic convertor

\subsection{Methodology}

A single phase single-species of carbon monoxide $(\mathrm{CO})$ with mass fraction of 0.4 for incompressible flow simulation with Air as the working fluid will be carried out. The mesh configuration chosen as MC-1 and MC-2 for the catalytic converter model with inlet and outlet conical portion length $90 \mathrm{~mm}$.

\section{Results and discussion}

We have considered the steel wire mesh configuration as MC-1 and MC-2 of catalytic converter having conical portion length $90 \mathrm{~mm}$ respectively.

\subsection{Catalytic convertor $-90 m m-M C-1$}

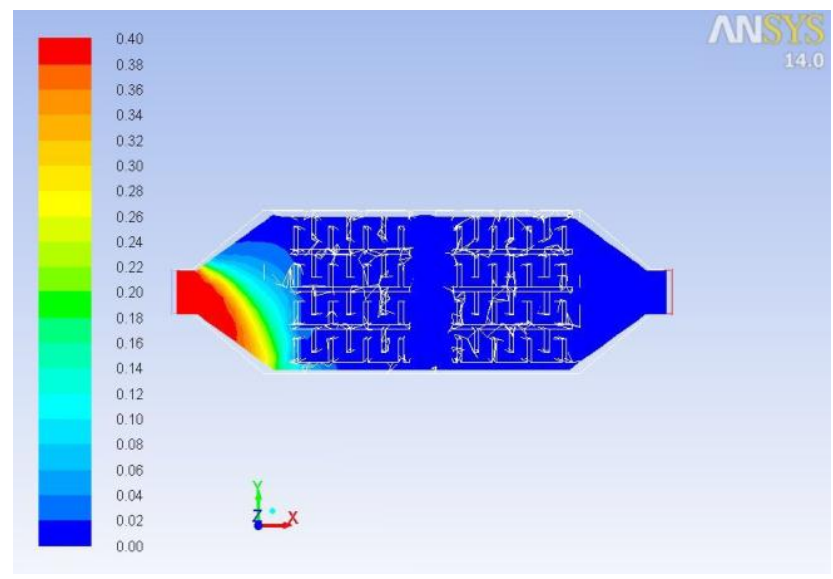

Fig.6 Contours of Mass fraction of CO (ppm) at $1 \mathrm{sec}$ 653 | International Conference on Advances in Mechanical Sciences 2014 


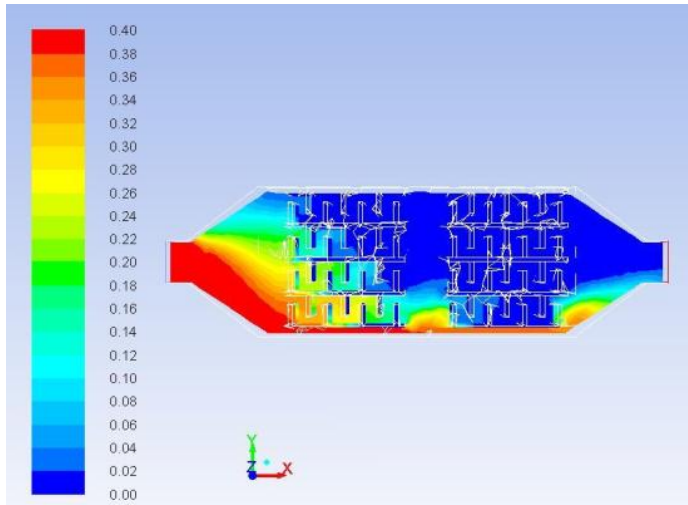

Fig.7 Contours of Mass fraction of $\mathrm{CO}(\mathrm{ppm})$ at $5 \mathrm{sec}$

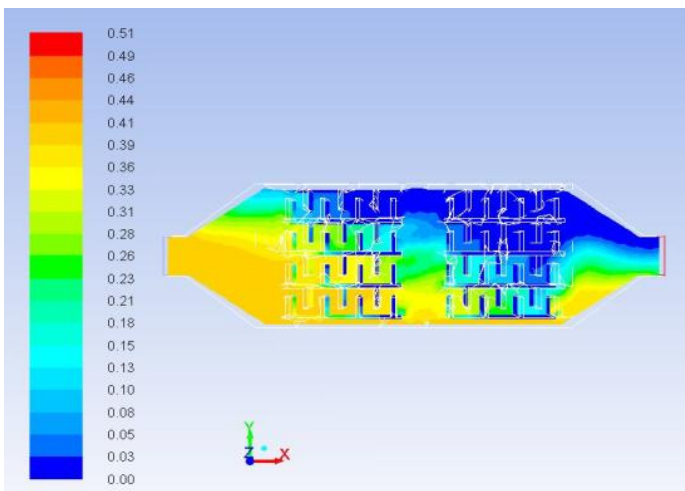

Fig.8 Contours of Mass fraction of $\mathrm{CO}(\mathrm{ppm})$ at10 sec

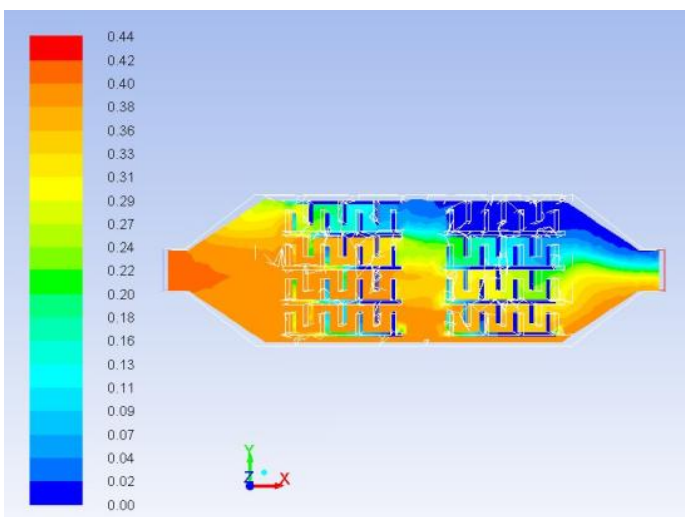

Fig.9 Contours of Mass fraction of CO (ppm) at15 sec

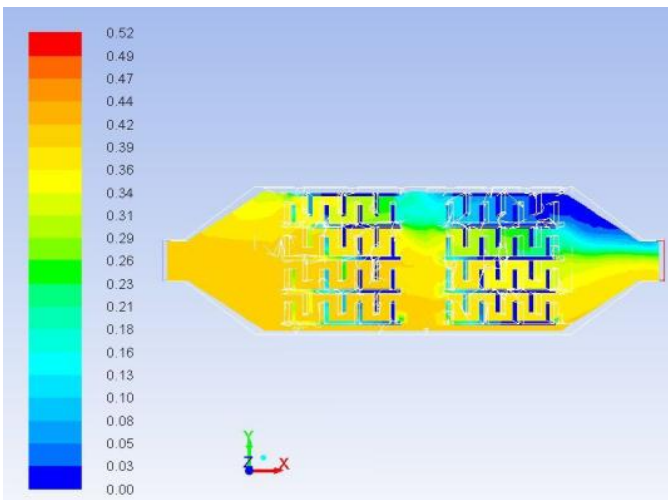

Fig.10 Contours of Mass fraction of CO (ppm) at $20 \mathrm{sec}$

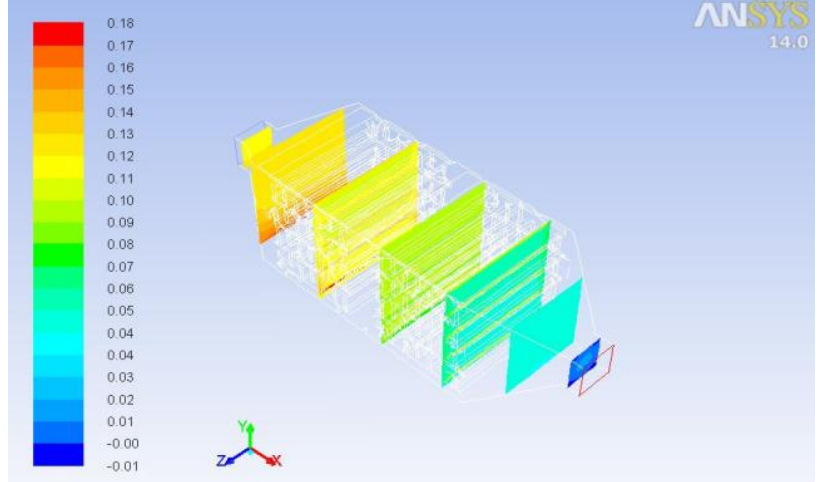

Fig.11 Contours of Static Pressure (pa) at $1 \mathrm{sec}$

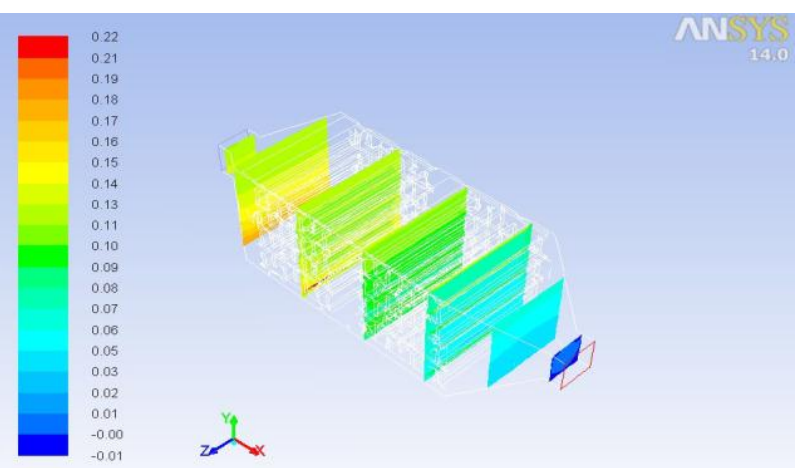

Fig.11 Contours of Static Pressure (pa) at $5 \mathrm{sec}$

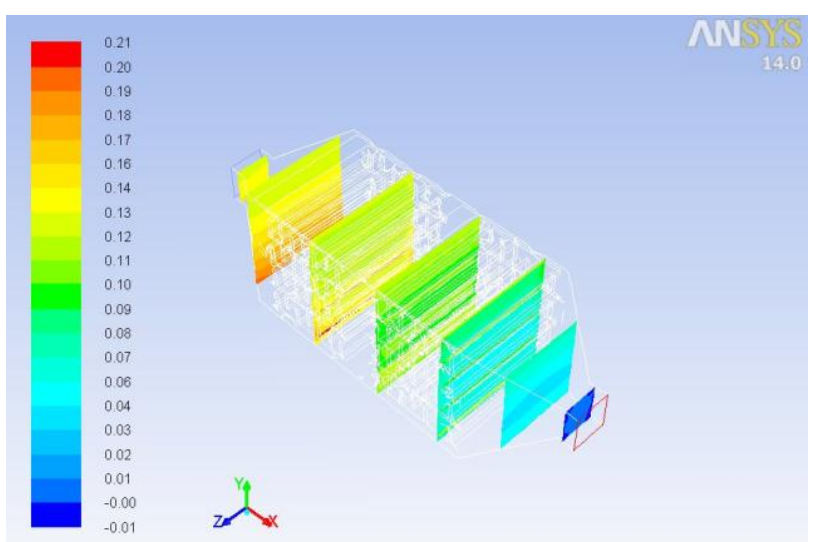

Fig.12 Contours of Static Pressure (pa) at $10 \mathrm{sec}$

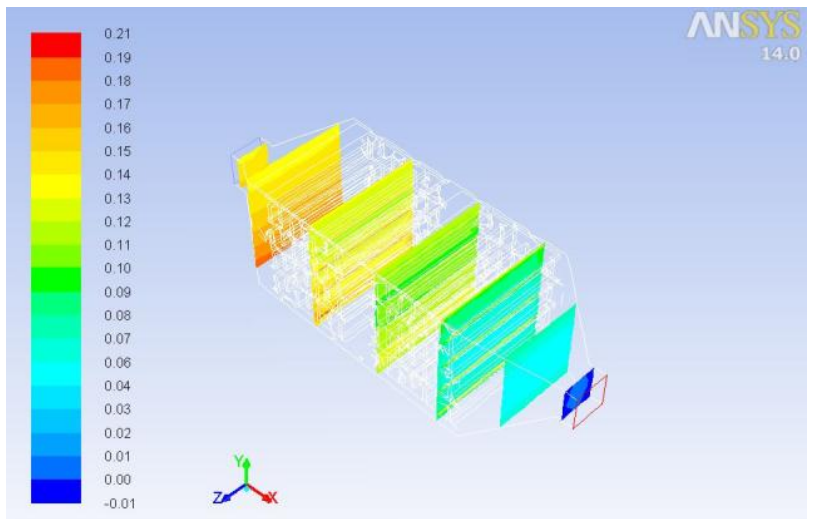

Fig.13 Contours of Static Pressure (pa) at $15 \mathrm{sec}$ 654 | International Conference on Advances in Mechanical Sciences 2014 


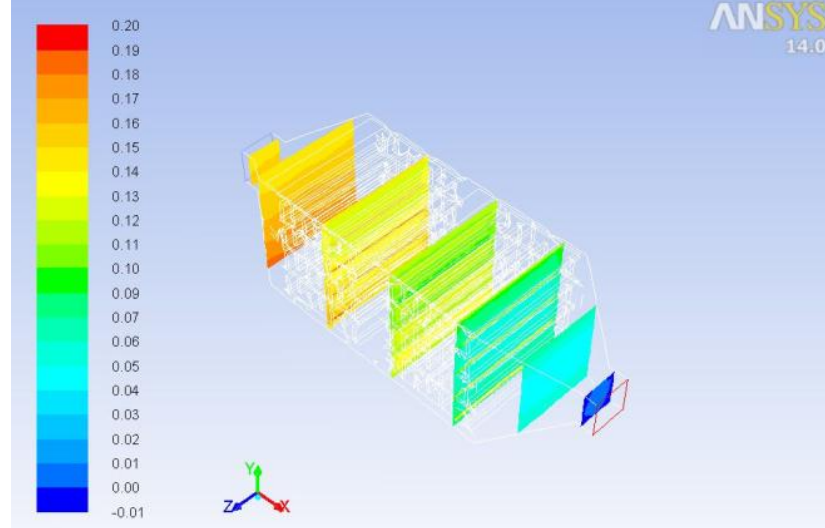

Fig.14 Contours of Static Pressure (pa) at $20 \mathrm{sec}$

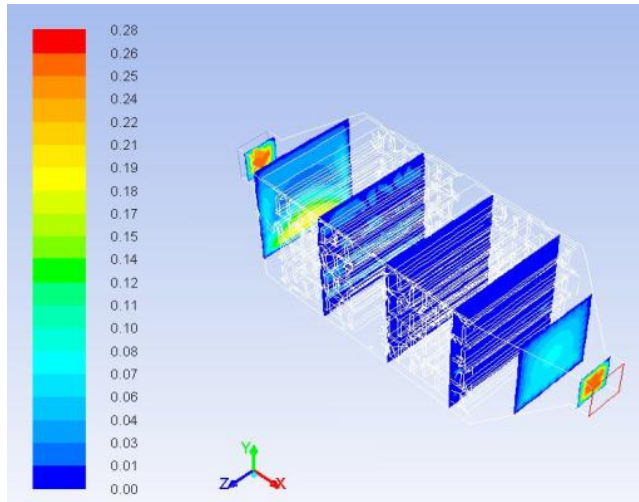

Fig.15 Contours of Velocity magnitude $(\mathrm{m} / \mathrm{sec})$ at $1 \mathrm{sec}$

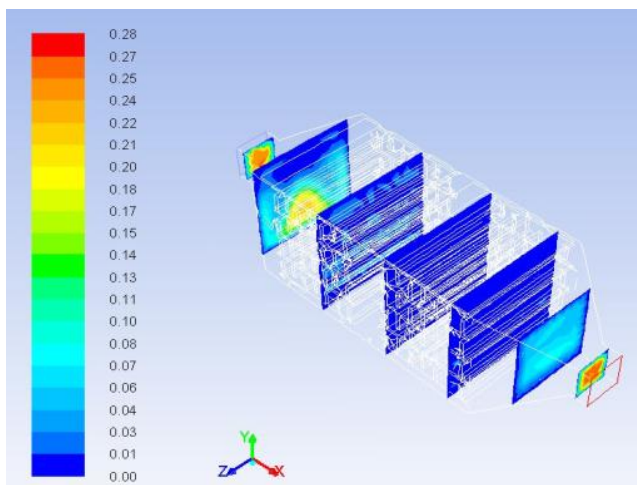

Fig.16 Contours of Velocity magnitude $(\mathrm{m} / \mathrm{sec})$ at $5 \mathrm{sec}$

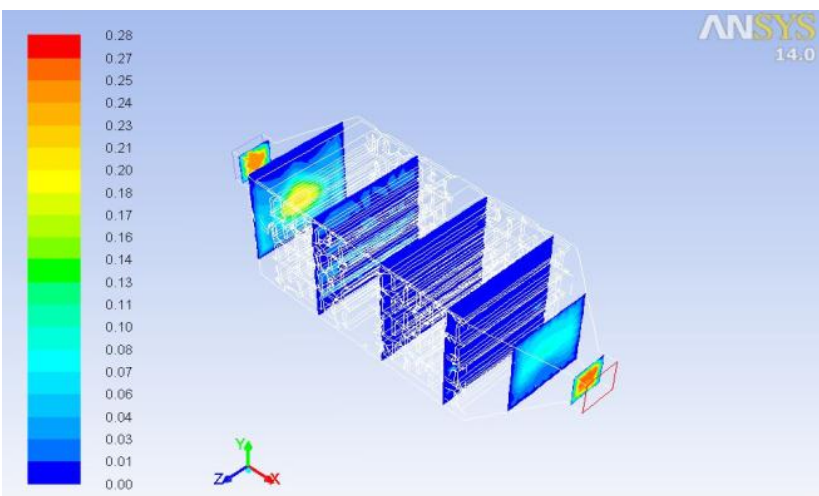

Fig.17 Contours of Velocity magnitude $(\mathrm{m} / \mathrm{sec})$ at $10 \mathrm{sec}$

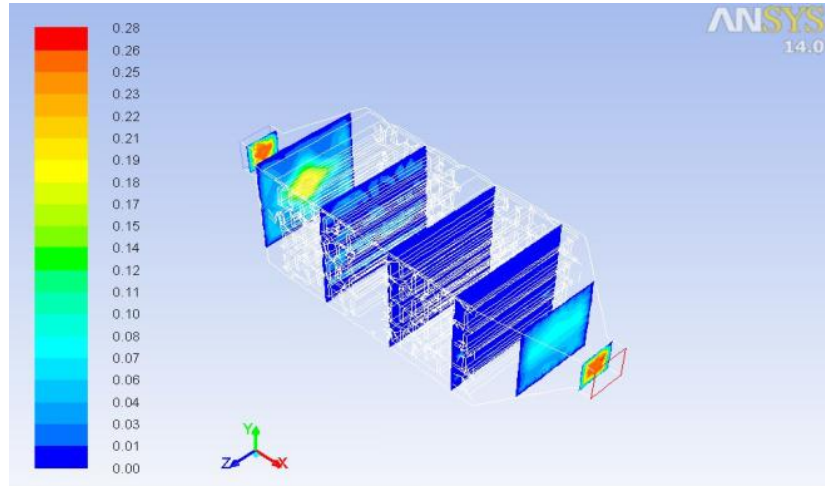

Fig.18 Contours of Velocity magnitude $(\mathrm{m} / \mathrm{sec})$ at $15 \mathrm{sec}$

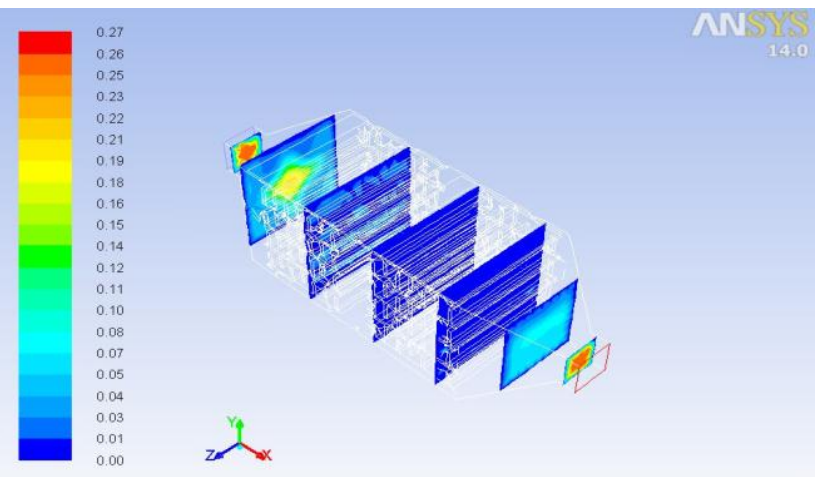

Fig.19 Contours of Velocity magnitude $(\mathrm{m} / \mathrm{sec})$ at $20 \mathrm{sec}$ 5.1 Catalytic convertor $-90 m m-M C-2$

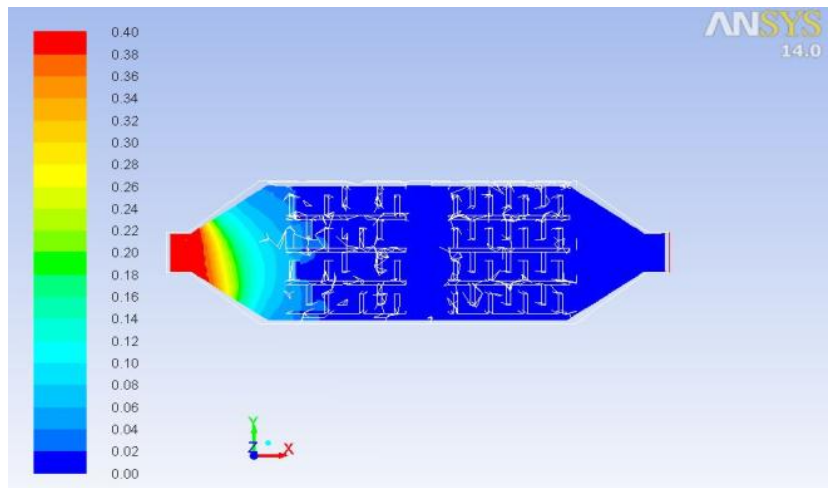

Fig.20 Contours of Mass fraction of CO (ppm) at $1 \mathrm{sec}$

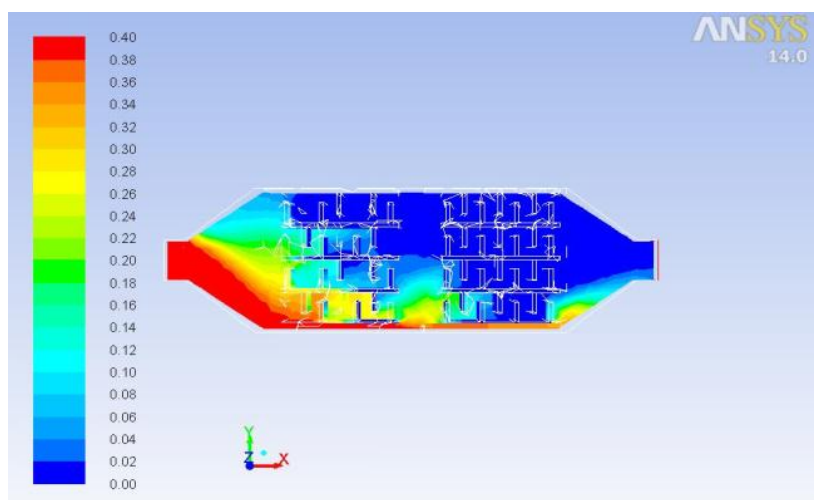

Fig.21 Contours of Mass fraction of CO (ppm) at $5 \mathrm{sec}$ 655 | International Conference on Advances in Mechanical Sciences 2014 


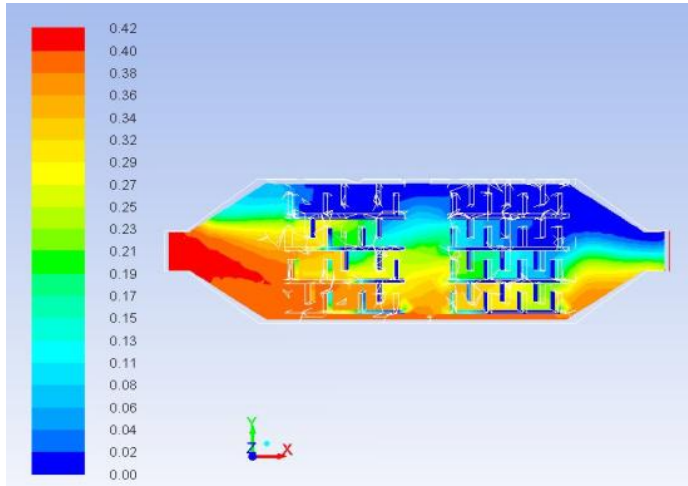

Fig.22 Contours of Mass fraction of CO (ppm) at $10 \mathrm{sec}$

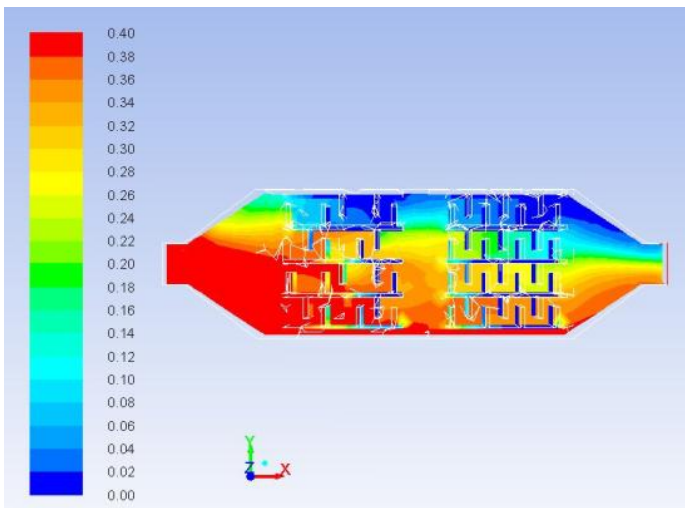

Fig.23 Contours of Mass fraction of CO (ppm) at $15 \mathrm{sec}$

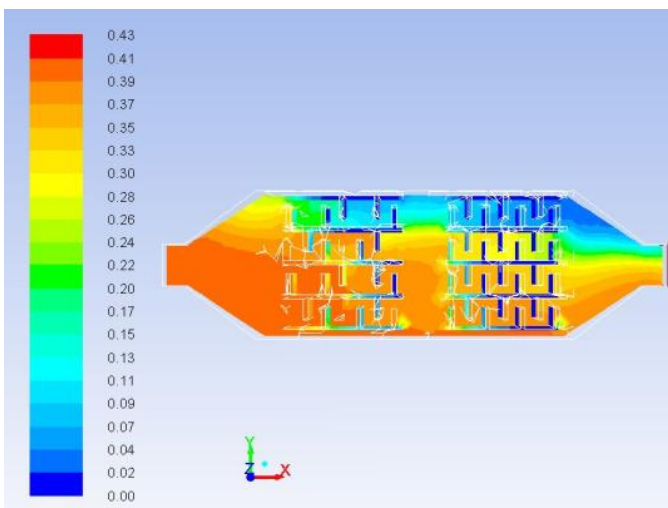

Fig.24 Contours of Mass fraction of CO (ppm) at $20 \mathrm{sec}$

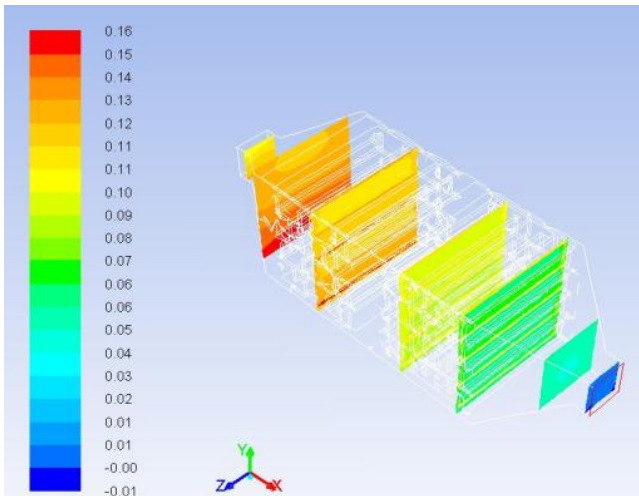

Fig.25 Contours of Static Pressure (pa) at $1 \mathrm{sec}$

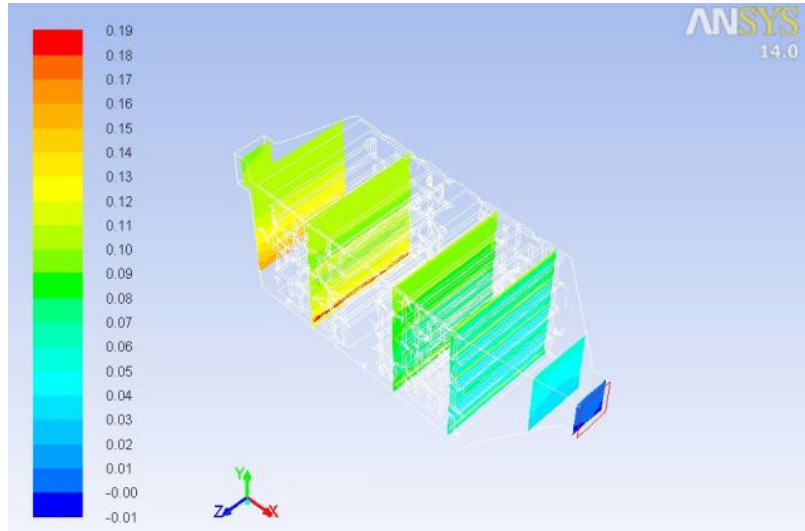

Fig.26 Contours of Static Pressure (pa) at $5 \mathrm{sec}$

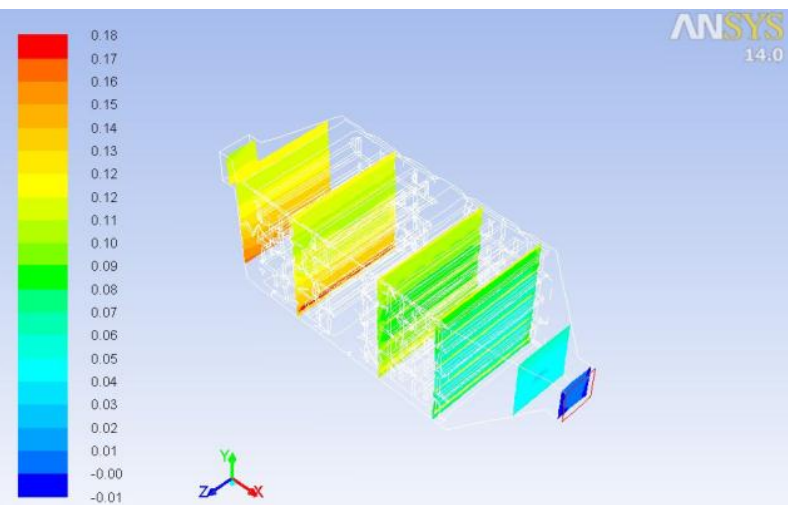

Fig.27 Contours of Static Pressure (pa) at $10 \mathrm{sec}$

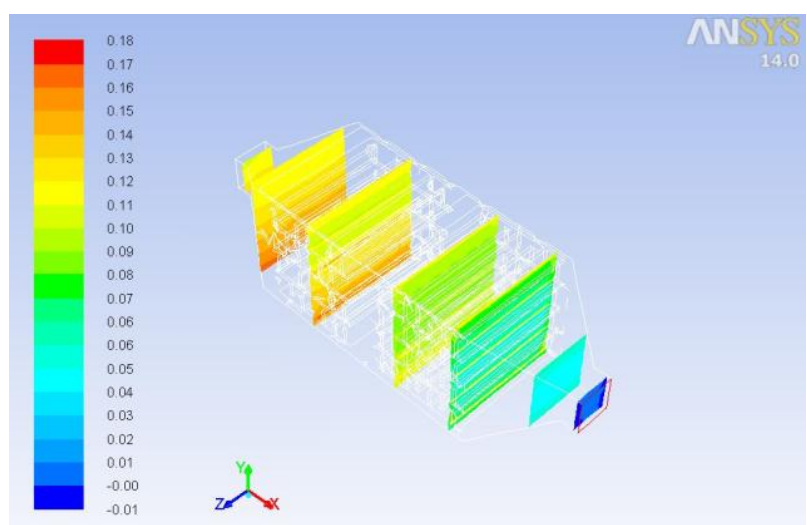

Fig.28 Contours of Static Pressure (pa) at $15 \mathrm{sec}$

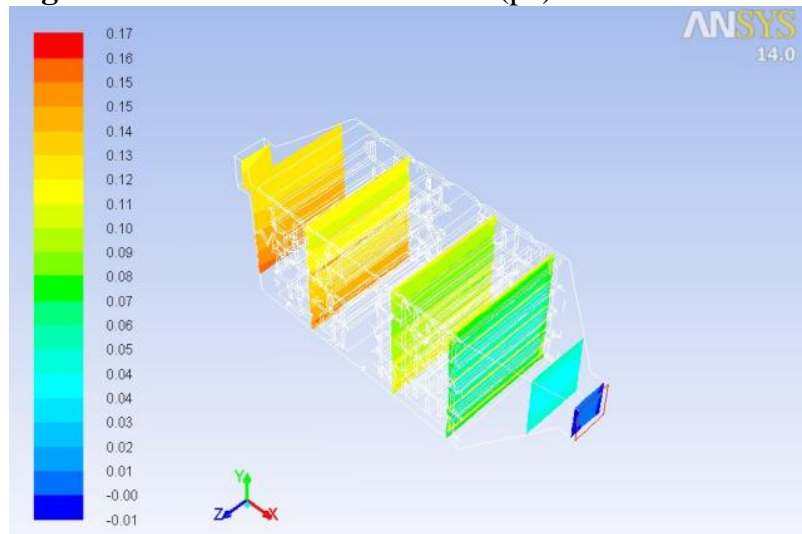

Fig.29 Contours of Static Pressure (pa) at $20 \mathrm{sec}$

656 | International Conference on Advances in Mechanical Sciences 2014 


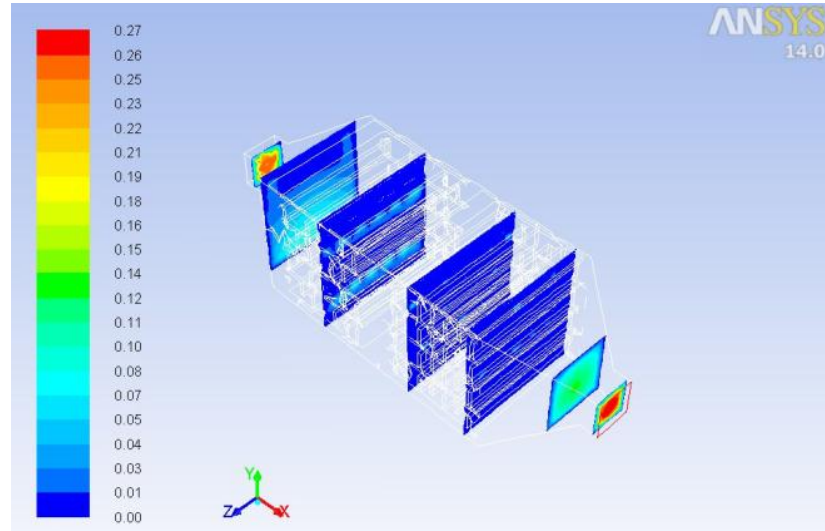

Fig.30 Contours of Velocity magnitude $(\mathrm{m} / \mathrm{sec})$ at $1 \mathrm{sec}$

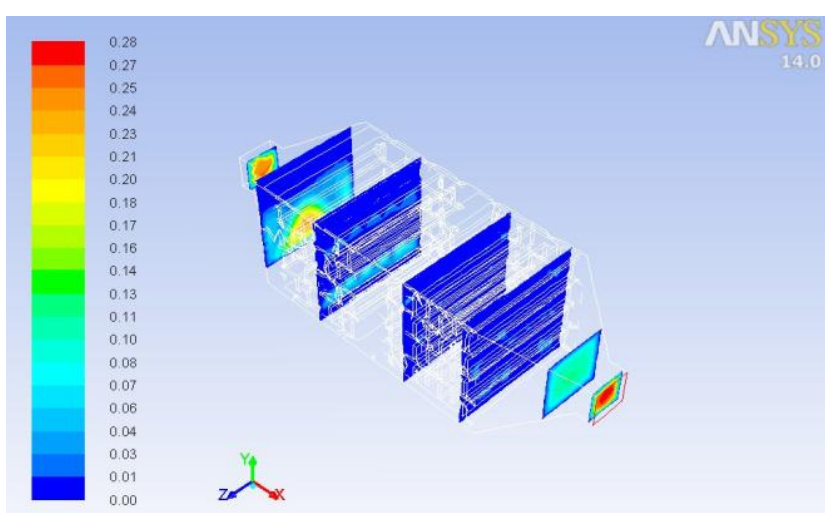

Fig.31 Contours of Velocity magnitude $(\mathrm{m} / \mathrm{sec})$ at $5 \mathrm{sec}$

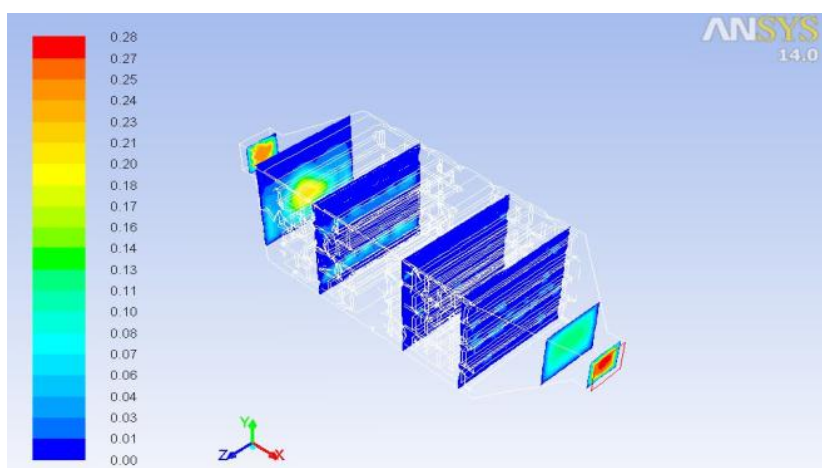

Fig.32 Contours of Velocity magnitude $(\mathrm{m} / \mathrm{sec})$ at $10 \mathrm{sec}$

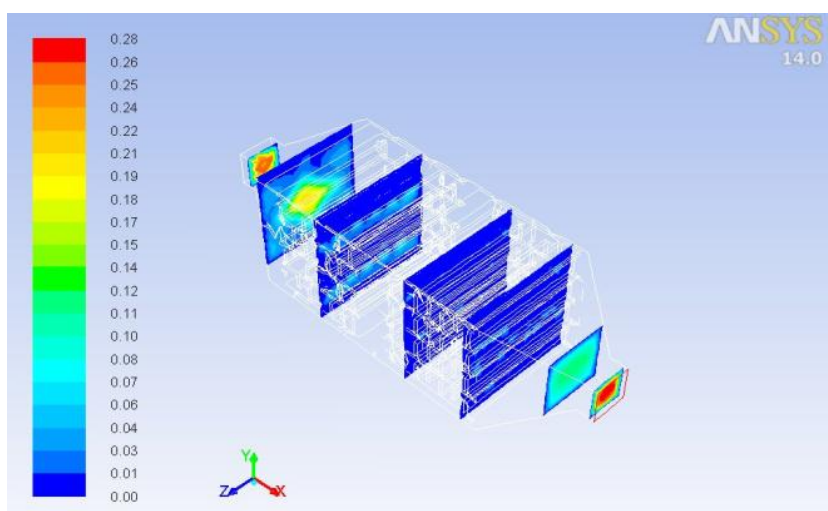

Fig.33 Contours of Velocity magnitude $(\mathrm{m} / \mathrm{sec})$ at $15 \mathrm{sec}$

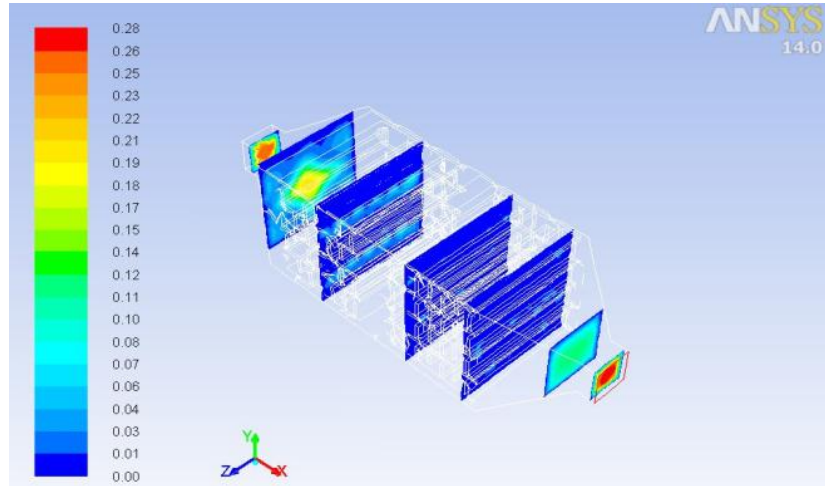

Fig.34 Contours of Velocity magnitude $(\mathrm{m} / \mathrm{sec})$ at $20 \mathrm{sec}$

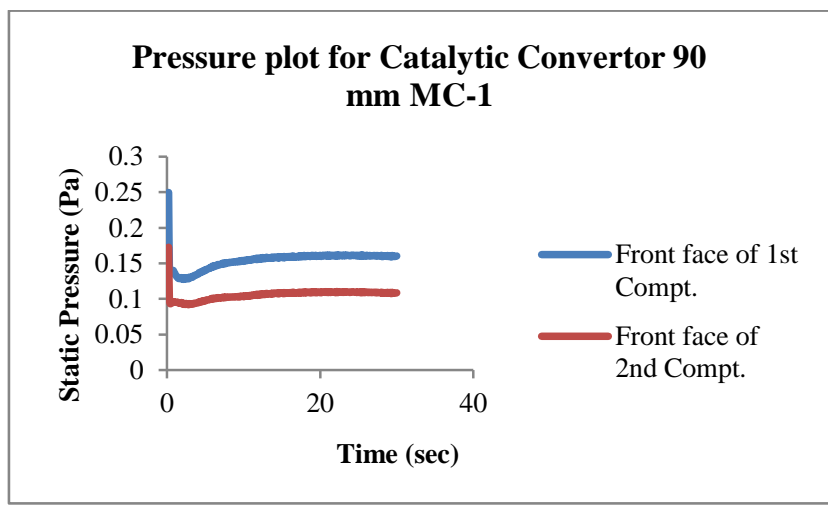

Fig.35 Pressure plot for MC-1

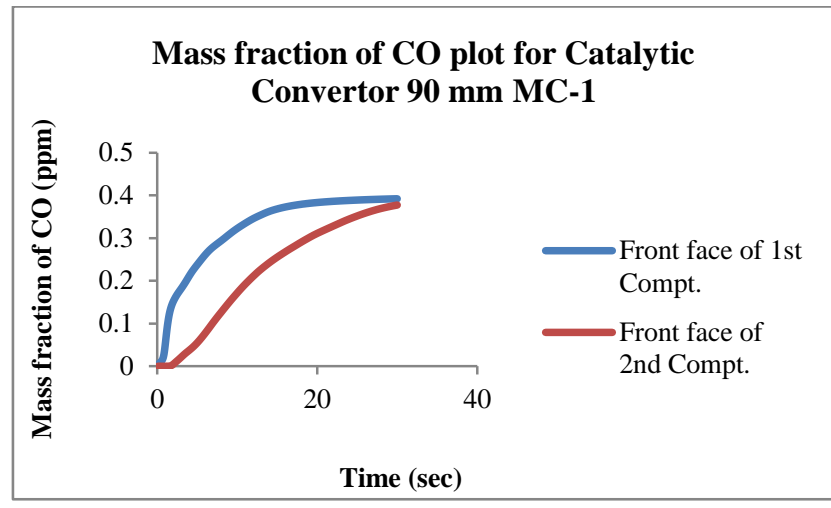

Fig.36 Mass fraction of CO plot for MC-1

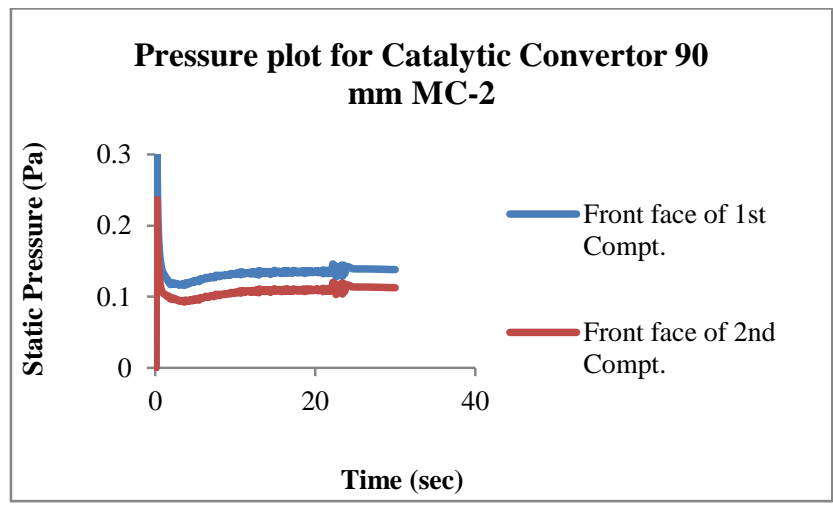

Fig.37 Pressure plot for MC-2

657 | International Conference on Advances in Mechanical Sciences 2014 


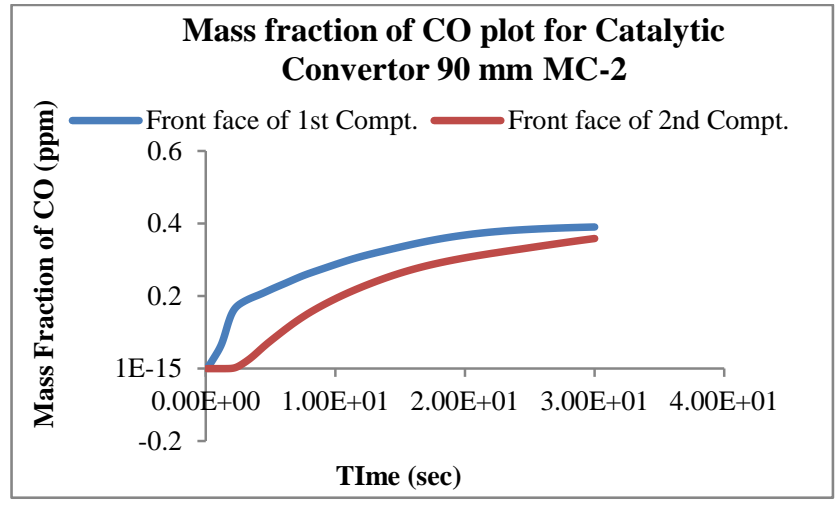

Fig.38 Mass fraction of CO plot for MC-2

\section{Conclusions}

By analyzing the pressure plots of MC-1 and MC-2 in figure 35 and 37 respectively. It is concluded that the catalytic converter $90 \mathrm{~mm}-\mathrm{MC}-2$ has the lowest pressure drop among the catalytic converter with different wire mesh grid sizes, due to lower pressure drop the fuel consumption become lower and volumetric efficiency becomes higher. The special shaped catalytic beads allow the exhaust gas to flow freely without making any obstruction or blocking. It helps to limit the back pressure to the minimum level resulting in better engine performance and fuel saving. The catalytic beads are very hard, no wear and tear of catalyst can take place, and hence long life of catalyst is assured.

\section{References}

L.Andreassi, S.Cordiner and V.Mulone,;Cell shape influence on mass transfer and backpressure losses in an automotive catalytic converter,SAE International, 2004-01-1837, 2004.

S.Rajadurai, S.Jacob, C.Serrell, R.Morin and Z.Kircanski,;Wiremesh Substrates for Oxidation.TWC and SCR Converters; GPC 2006 Advanced Propulsion and Emission

F.Ekstrom and B.Andersson, Pressure drop of monolithic catalytic converters experiments and modeling SAE Internationals, 2002-01-1010, 2002.

S. Narasimha Kumar, K. Kishor,M. V. S.Murali Krishna and P.V. K. Murthy, Studies on Exhaust Emissions from CopperCoated Gasohol Run Spark Ignition Engine with Catalytic Converter International Scholarly Research Network ISRN Mechanical Engineering Volume 2011.

A.K.M. Mohiuddin and Muhammad Nurhafez - Experimental Analysis and Comparison of Performance Characteristics of Catalytic Converters Including Simulation, International Journal of Mechanical and Materials Engineering (IJMME), Vol. 2 (2007), No. 1, 1-7.

PL.S. Muthaiah, Dr.M. Senthil Kumar, Dr. S. Sendilvelan - CFD Analysis of catalytic converter to reduce particulate matter and achieve limited back pressure in diesel engine, Global journal of researches in engineering - A: Classification(FOR) 091304,091399, Vol.10 Issue 5 (Ver1.0) October 2010. 